\title{
PERILAKU REMAJA DALAM PEMANFAATAN PROGRAM PELAYANAN KESEHATAN PEDULI REMAJA (PKPR) DI PUSKESMAS JUMPANDANG BARU
}

\author{
Santi $^{1}$, Cheristina ${ }^{2}$ \\ Program Studi S1 Keperawatan Stikes Kurnia Jaya Persada ${ }^{1,2}$ \\ santysukses195@gmail.com ${ }^{1}$,Titincheristina@gmail.com²
}

\begin{abstract}
ABSTRACK
The Youth Care Health Care Program (PKPR) is a health service to adolescents through special treatment tailored to the desires, tastes and needs of adolescents.This research aims to find out the behavior of adolescents in the utilization of PKPR program on predisposition factor,supporting factors and driving factors. This study uses qualitative design with phenomenological approach. This research was conducted for 2 months from July to August 2020 Data collection with focus group discussion (FGD) and indepth interview. FGD is performed on thirteen students who are a target school of Public center. In-depth interviews were conducted on seven ordinary informants, namely community youth who utilize services in health centers, four key informants namely counselors, peer escorts, field officers and PKPR program holders.The results of this study show that the behavior of adolescents in the utilization of PKPR program is not maximal, there are several factors that affect visits to the public center low and less maximal utilization of PKPR. The potential factors related to knowledge have not been thorough, the teenager is not fully aware of the service pkpr in public center so have not utilized the service. Supporting factors related to health care facilities are adequate but need to be effective especially in schools, the driving factors related to the support of health workers have not fully embraced adolescents as a whole.This research can be concluded that health officials further enhance socialization to all adolescents in order to know the importance of utilizing the program and providing support by embracing the youth as a whole, so that the PKPR program in new Jumpandang Public Center can run optimally.
\end{abstract}

Keywords $\quad$ : Adolescents, Behavior, Utilization of PKPR.

\begin{abstract}
ABSTRAK
Program Pelayanan Kesehatan Peduli Remaja (PKPR) merupakan pelayanan kesehatan kepada remaja melalui perlakuan khusus yang disesuaikan dengan keinginan, selera dan kebutuhan remaja. Penelitian ini bertujuan untuk mengetahui perilaku remaja dalam pemanfaatan program PKPR tentang faktor predisposisi, faktor pendukung dan faktor pendorong. Penelitian ini menggunakan rancangan kualitatif dengan pendekatan fenomenologi. Pene;itian ini dilaksanakan 2 bulan dari bulan Juli sampai Agustus 2020, Pengumpulan data dengan focus group discussion (FGD) dan wawancara mendalam (indepth interview). FGD dilakukan pada tiga belas siswa yang merupakan satu sekolah binaan Puskesmas. Wawancara mendalam dilaksanakan pada tujuh informan biasa yakni remaja komunitas yang memanfaatkan pelayanan di puskesmas, empat informan kunci yaitu konselor, pendamping sebaya, petugas lapangan dan pemegang program PKPR. Hasil penelitian ini menunjukkan bahwa perilaku remaja dalam pemanfaatan program PKPR belum maksimal, ada beberapa faktor yang mempengaruhi kunjungan ke puskesmas rendah dan kurang maksimalnya pemanfaatan PKPR. Faktor pemungkin terkait pengetahuan belum menyeluruh, remaja belum sepenuhnya mengetahui adanya layanan PKPR di Puskesmas sehingga belum memanfaatkan layanan. Faktor pendukung terkait fasilitas pelayanan kesehatan sudah memadai namun perlu diefektifkan terutama di sekolah, Faktor pendorong terkait dukungan petugas kesehatan belum sepenuhnya merangkul remaja secara keseluruhan.
\end{abstract}


Berdasarkan hasil penelitian yang diperoleh tersebut maka dapat disimpulkan bahwa petugas kesehatan lebih meningkatkan lagi sosialisasi ke semua kalangan remaja agar dapat mengetahui pentingnya pemanfaatan program dan memberikan dukungan dengan merangkul remaja secara keseluruhan, sehingga program PKPR di Puskesmas Jumpandang Baru dapat berjalan dengan optimal.

Kata Kunci : Perilaku, Remaja, Pemanfaatan PKPR.

\section{PENDAHULUAN}

Masa remaja merupakan periode terjadinya pertumbuhan dan perkembangan secara dinamis dan pesat baik fisik, psikologis, intelektual, sosial, dan tingkah laku seksual yang dikaitkan dengan mulai terjadinya pubertas. Masa ini adalah periode transisi dari masa kanak-kanak menuju dewasa. Pola karakteristik pesatnya tumbuh kembang ini menyebabkan remaja memiliki rasa keingintahuan yang besar, menyukai petualangan, tantangan, dan cenderung berani mengambil risiko tanpa pertimbangan yang matang, sehingga dalam masa remaja banyak masalah kesehatan yang dihadapi yang berkaitan dengan perilaku (Atuyambe et al., 2015).

Survei Demografi Kesehatan Indonesia (SDKI) tentang kasus remaja, menunjukan bahwa jumlah pria merokok dari 53\% meningkat menjadi $55 \%$ dan $1 \%$ wanita merokok. $70 \%$ pada pria dan $58 \%$ mulai minum alkohol pada kelompok umur 15-19 tahun. Secara umum presentasi wanita yang pernah menggunakan obat terlarang kurang dari $1 \%$ dan $5 \%$ dari pria menggunakan obat terlarang diantaranya $2 \%$ menggunakan cara dihisap dan $3 \%$ dengan cara diminum dan ditelan. SDKI melaporkan unsur pertama kali berhubungan seksual remaja 17 tahun merupakan unsur tertinggi baik wanita maupun pria (19\%) yang melakukan hubungan seksual pertama kali (BKKBN dan BPS, 2017).

Di Kota Makassar permasalahan yang berhubungan dengan kesehatan remaja masih memperihatinkan yakni tercatat angka penderita HIV/AIDS masih cukup tinggi. Data dari Dinas Kesehatan Propinsi hingga Juni 2019, secara kumulatif jumlah kasus
AIDS tercatat sebanyak 226.483 kasus. Dilihat dari kelompok umur, pengidap terbesar pada kelompok umur 15-29 tahun yaitu sebanyak $36,43 \%$, disusul dengan kelompok umur 30-39 tahun sebanyak $34,53 \%$. Sedangkan faktor penyebabnya telah bergeser dimana transmisi HIV secara heteroseksual menjadi penyebab utama (76,3\%), disusul oleh transmisi melalui penggunaan suntik tidak aman $(16,3 \%)$ dan kemudian oleh transmisi HIV secara homoseksual $(2,2 \%)$, sementara cara penularan kembali ke transmisi secara seksual.

Berbagai kasus ditemukan dari informasi data kumulatif kunjungan remaja di Puskesmas Jumpandang Baru untuk tahun 2019 yang cakupannya masih sangat rendah, remaja yang menderita HIV AIDS sejumlah 11 orang dan remaja yang menderita IMS sejumlah 35 orang serta pengguna narkoba di kalangan remaja sejumlah 4 orang. Pemanfaatan Program Pelayanan Kesehatan Peduli Remaja di Puskesmas Jumpandang Baru Kota Makassar yang ditinjau dari segi faktor predisposisi, faktor pendukung, dan faktor pendorong. Tujuan diadakan Penelitian ini adalah memperoleh dan menganalisis informasi mengenai perilaku remaja dalam pemanfaatan program pelayanan kesehatan peduli remaja di Puskesmas Jumpandang baru kota Makassar (Baso, 2019)

\section{METODE}

Jenis penelitian yang digunakan adalah penelitian kualitatif dengan pendekatan fenomenologi yang bertujuan menganalisis informasi dari informan yang berlokasi di Puskesmas Jumpandang Baru kota Makassar. 
Partisipan dalam penelitian ini adalah remaja 10-19 tahun, Penelitian dilaksanakan dengan informan sebanyak 24 orang dimana jumlah informan biasa sebanyak 20 responden dan informan kunci sebanyak 4 responden dengan teknik pengumpulan data menggunakan pedoman wawancara mendalam, observasi, focus group discussion (FGD) dan catatan lapangan (field note) dengan pemilihan informan yang dapat memberikan informasi yang akurat tentang variabel yang diteliti Sebelum dianalisis peneliti membaca transkrip dan catatan lapangan dengan menggunakan content analisis dan interprestasi kemudian disajikan dalam bentuk narasi (Sugioyo, 2010)

\section{HASIL}

Penelitian ini telah dilaksanakan di Puskesmas Jumpandang Baru Kecamatan Tallo Kota Makassar yang merupakan salah satu dari 47 Puskesmas yang berada pada wilayah kerja Dinas Kesehatan Kota Makassar didirikan pada tahun 1968 mempunyai tujuan yaitu melayani serta memberikan gambaran kondisi dan situasi kesehatan masyarakat dalam wilayah kerja puskesmas yang berkualitas secara optimal dalam mendukung pencapaian tujuan pembangunan kesehatan Kota Makassar yang dilaksanakan selama 2 bulan dari bulan Juli sampai Agustus 2020.

Diagnosis Perilaku Kesehatan dapat dipengaruhi oleh 3 faktor yaitu faktor predisposisi, faktor pemungkin dan faktor penguat.

1. Faktor predisposisi terkait pengetahuan remaja tentang PKPR

a. Pemahaman informan mengenai program pelayanan kesehatan peduli remaja belum menyeluruh karena hanya remaja komunitas saja yang mengetahui keberadaan PKPR, beberapa remaja belum sepenuhnya mengetahui adanya layanan belum memanfaatkan layanan tersebut. Hal ini diperoleh melalui wawancara mendalam dan FGD. “...setauku toh pelayanan peduli remaja itu ada di puskesmas, terus saya tau ada ini layanan lewat sosial media yang tentunya bisa melayani remaja dengan ramah jadi saya ke tempat ini, mungkin banyak di puskesmas yang lain cuman saya taunya disini ji..."(LA, 19 thn, )

Dan hal ini didukung oleh pernyataan informan lainnya yang menyatakan bahwa program PKPR merupakan program khusus untuk remaja, dan merupakan sasaran utama dari program PKPR sehingga pemanfaatan harus menyeluruh kesemua remaja seperti kutipan berikut :

“...kalo yang saya pahami toh mengenai ini program pkpr dikhususkan memang untuk remaja karena sasarannya program dan tidak semua remaja yang bermasalah datang ke puskesmas, remaja itu kan kalo tdk ada yang pengaruhi tidak bakalan datang, kadang juga ada yang nakal tapi kan remaja labil dan berfikir untuk apa datang kalo saya masih sehat ngapain kesini, padahal sebenarnya mnda perlu yang bermasalah karena ada juga pencegahannya ini PKPR dan itu mi guna ta kita yang lama maki manfaatakan ini layanan untuk sampaikan ke remaja yang lain..." (AB.19 thn, FGD)

b. Pemanfaatan Program PKPR sangat bermanfaat bagi remaja sehingga harus di manfaatkan secara optimal. Karena remaja yang telah memahami program PKPR akan terdorong untuk memanfaatkan layanan PKPR. Dan hal ini didapatkan melalui wawancara sebagai berikut :

“...Iya saya sudah manfaatkanki ini PKPR sejak satu tahun enam bulan, yang saya manfaatkan itu pelayanan konseling, KIE dan pemeriksaan kesehatan semacam test HIV dan Narkoba..." (IS, WM) 
Namun, dari hasil FGD didapatkan informasi yang berbeda mengenai pengetahuan dalam pemanfaatan program PKPR. Informan menyatakan bahwa tidak mengetahui keberadaan program PKPR, tetapi hanya mengetahui PIK KRR yang di peroleh dari guru BK kutipan ini sebagai berikut:

“...Saya mnda tau kak apa itu program PKPR, yang saya tau itu PIK KRR ji di sekolah ini, tapi itupun dari guru BK yang buat kak..." (RE 15 thn FGD)

c. Penggunaan layanan Program pelayanan Kesehatan Peduli Remaja (seperti layanan koseling, pemberian Komunikasi, Informasi dan Edukasi)di dalam atau di luar gegung Puskesmas.

Informasi lainnya terkait ketidakpahaman informan terhadap program PKPR yang menyatakan bahwa wadah untuk konseling di sekolah telah tersedia tetapi remaja yang tidak peduli dengan keberadaannya begitupun dengan kunjungan ke Puskesmas

“..Menurutku toh kak karena tidak di pahamnya mi itu mengenai program PKPR makanya di sekolah saja na jarang ada remaja yang ke tempat konseling sama di UKS padahal ada mie wadahnya tersedia, apalagi untuk pergi ke puskesmas, jelas mie tidak peduli" (AA 15 thn FGD).

Hal ini sesuai dengan pernyataan pemegang program PKPR bahwa remaja sangat susah untuk dibina dan tidak peduli terhadap kegiatan KIE maupun kelas edukasi yang dilaksanakan disekolah serta belum adanya pelatihan mengenai cara menangani remaja. Berikut kutipan wawancara :

“...kalo remaja di sekolah yang betulbetul mau di bina yah bagus tapi kalo sekolah yang tidak bisa di bina yah susah juga karena meskipun ada penyuluhan dan kelas edukasi remajanya tidak peduli sama sekali dengan ini PKPR, sangat susah juga untuk dikumpulkan remajanya, dan kayaknya mereka memang tidak butuh dan jujur kami juga sebenarnya tidak mendapatkan pelatihan khusus dari dinkes mengenai cara menangani permasalahan remaja..." (Pemegang program 41 thn WM)

Informasi yang di peroleh dari hasil wawancara mendalam dan FGD mengenai pengetahuan remaja dalam program pelayanan kesehatan peduli remaja menunjukkan bahwa informan belum sepenuhnya mengetahui tentang pemanfaatan program tersebut.

2. Faktor pemungkin terkait fasilitas pelayanan kesehatan

a. Bentuk pelaksanaan pelayanan kesehatan peduli remaja yang dilaksanakan di puskesmas, Berikut hasil wawancara berikut ini:

“...Bentuk fasilitasnya yang ada di puskesmas itu ada konseling,pemeriksaan penunjang seperti test HIV, IMS sama terapi Metadone (narkoba) pemberian KIE dan masih banyak lagi, kalo menurutku toh lengkap sekali mi fasilitasnya disini..." (MR 19 thn WM)

b. Tanggapan Informan terkait fasilitas PKPR yang ada di Puskesmas,apakah sudah memadai atau belum, berikut hasil wawancaranya

“...Memadai sekali mi fasilitasnya karena lengkap mi semua tinggal di tingkatakan lagi pemanfatannya supaya lebih menarik apalagi layanannya tidak membebankan..." (AB 19 thn, WM)

c. Ketersediaan media yang digunakan seperti poster, buku saku dan brosur mengenai kesehatan yang diberikan pada pelaksanaan, berikut kutipan wawancaranya :

“...Iya tersedia poster sama pamflet emmm semacam KIE, karena saya sudah 10 kali konseling jadi saya dapat kan buku saku dan brosur tentang kesehatan trus saya lagi yang sampaikan ke remaja di luar sana, 
misalkan temanku untuk manfaatkan ini pelayanan..." (NK 18 thn WM)

Hal ini didukung oleh pernyataan konselor sebagai pemerhati remaja dan memilki tugas untuk memberikan informasi terkait kesehatan remaja didalam gedung puskesmas maupun di luar gedung puskesmas yang mengungkapkan bahwa:

"...fasilitas di dalam puskesmas ini sudah memadai termasuk ruang konseling, ruang methadone, ruangan IMS, ruangan periksa, ruang obat, ruang laboratorium, ruang perawatan sementara, adapun untuk remaja di sekolah itu kita penjaringannya setiap tahun juga melalui KIE terkait", (Konselor WM 55 thn)

HIV AIDS dan Narkoba sebagai promosi pencegahan penyakit di SMK 5 Makassar hanya saja belum di informasikan secara khusus mengenai layanan PKPR di puskesmas makanya rata-rata remaja secara umum saja yang manfaatkan layanan konselingnya...'

d. Pernyataan berbeda dari informan mengenai ketidaklengkapan fasilitas pelaksanaan program PKPR di sekolah, menurut informan fasilitasnya tidak efektif, sebagaimana hasil FGD berikut ini :

“...Fasilitas pelayanannya itu berupa pemberian KIE di sekolah materinya mengenai HIV AIDS sama Narkoba, begitu ji setiap tahun itupun tidak efektif karena satu ruangan seratus orang, sangat pengap juga sulit untuk bertanya, belum memadai karena tidak ada informasi mengenai layanan PKPR $d$ puskesmas..." (NA 15 thn FGD )

Minimnya fasilitas penunjang di sekolah binaan pada saat pemberian KIE diungkapkan pula oleh informan lainnya bahwa tidak tersedianya brosur dan juga poster mengenai kesehatan, berikut kutipan wawancaranya :

“...Pada saat pemberian KIE tidak pernah ada brosur sama poster mengenai kesehatan remaja, minim sekali fasilitas penunjangnya,," (FA 15 thn,WM)

Penjelasan informan diatas mengenai fasilitas pelayanan kesehatan terkait pemanfaatan program PKPR di puskesmas sudah memadai namun perlu diefektifkan terutama di sekolah agar pelaksanaan program PKPR dapat berjalan maksimal.

3. Faktor penguat terkait dukungan petugas kesehatan remaja tentang PKPR

a. Dukungan petugas terhadap pemanfaatan program PKPR. Berikut kutipan wawancara:

“...sangat mendukung sekali petugasnya apalagi ramah juga sama kita jadi nyamanki untuk bersosialisasi dan tidak ada diskriminasi sama sekali..." (KV 19 thn WM)

b. Informasi tentang pentingnya pemanfaatan PKPR yang diberikan oleh petugas kesehatan

“...Iya saya selalu dapat informasi dari petugas yang membahas masalah remaja dengan solusinya makanya di situ mi banyak saya dapatkan informasinya banyak belajar ka juga, karena kalo orang hiv positif kayak saya harus banyak belajar dan tidak terpuruk..." (MR 19 thn WM )

c. Sikap tenaga kesehatan terhadap dalam pemberian pelayanan kesehatan, seperti wawancara berikut :

“...sikapnya tenaga kesehatan sangat peduli sama remaja, mereka selalu pantau ki lewat sms atau sosial media kalo malas ki lagi datang berkunjung ke puskesmas..." (NK 19 thn WM)

Pernyataan ini didukung oleh pendamping sebaya yang bertugas mendampingi remaja dalam pemanfaatan program PKPR bahwa tidak satupun remaja yang menjadi dampingannya mengeluh terkait dukungan petugas yang tidak ramah, karena petugas sangat memahami jiwa remaja tersebut, berikut kutipan wawancaranya : 
"...saya selama 6 tahun menjadi pendamping sebaya tidak ada sedikitpun yang saya dampingi mengalami kesulitan apalagi mengeluh mengenai dukungan petugasnya, bayangkan orang yang drop sekalipun karena HIV atau narkoba saja disini disediakan ruangan perawatan sementaranya, meskipun berkasnya belum masuk ke layanan tapi sudah dilayani duluan untuk konseling nah ini perbedaannya dengan puskesmas yang lainnya, sejauh ini belum ada petugas satupun yang tidak welcome sama remajanya karena mereka betulbetul paham mngenai jiwanya ini remaja, pokoknya semuanya ramah..." (Pendamping Sebaya 35 thn WM)

Namun, didapatkan informasi yang berbeda pula melalui FGD terkait dukungan petugas dalam pemanfaatan program PKPR di sekolah yakni petugas tidak mendukung dengan cara melakukan pengenalan lebih dekat kepada remaja pada saat pemberian KIE, hal ini dapat terungkap dari wawancara berikut ini :

“...Tidak mendukung menurut saya petugasnya karena tidak berbaur sama remajanya cuman pemberian KIE saja di sekolah tanpa ada pengenalan lebih dekat dengan petugasnya.." (SM 15 thn)

Informasi lainnya dari informan yang mengungkapkan bahwa pentingnya pemanfaatan program PKPR tidak disampaikan langsung oleh petugas, hanya pemberian KIE mengenai HIV AIDS dan Narkoba, berikut kutipannya

“...secara langsung dari petugas tidak pernah dapat informasi mengenai manfaat PKPR karena mereka hanya datang memberikan materi HIV AIDS dan Narkoba saja.." (SR 16 thn FGD ) Sikap petugas yang tidak ramah dan jarang senyum dalam melayani remaja pada pelaksanaan PKPR disekolah yang seharusnya dapat mengayomi remaja, agar mau dan mampu memanfaatkan layanan PKPR hal tersebut diungkapkan oleh informan berikut wawancaranya :

“...sikapnya tidak ramah karena jarang senyum dalam melayani remaja, semacam cuek juga padahal dia kan harusnya dapat mengayomi remaja...(MA, 16 thn FGD)

Berdasarkan hasil wawancara mendalam dan FGD tersebut, menunjukkan bahwa dukungan petugas kesehatan dalam pemanfaatan program PKPR belum merangkul remaja secara keseluruhan, hal tersebut disebabkan karena perlakuan yang didapatkan remaja dari pertugas kesehatan ketika memberikan penyuluhan di sekolah binaan tidak ramah dan cuek terhadap kebutuhan kesehatan remaja, berbeda dengan dukungan petugas terhadap remaja yang berkunjung di Puskesmas Jumpandang Baru dalam mendapatkan pelayanan kesehatan yang menunjukkan bahwa sikap petugas ramah dan tidak mendiskriminasi dalam memberikan pelayanan kesehatan, sehingga hal tersebut dapat mempengaruhi perilaku remaja terhadap pemanfaatan program PKPR.

\section{PEMBAHASAN}

Pengetahuan informan mengenai program PKPR berbeda dengan remaja yang berada di sekolah sebagai binaan Puskesmas Jumpandang Baru karena mereka mengeluhkan tentang kurangnya informasi mengenai keberadaan layanan PKPR yang belum di dapatkan dari petugas kesehatan, Informan hanya mengetahui PIK KRR yang dikelolah oleh guru BK, serta ketidakpahaman informan terhadap program PKPR yang menyatakan bahwa wadah untuk konseling di sekolah telah tersedia, akan tetapi remaja yang tidak peduli dengan keberadaannya karena tidak adanya ajakan langsung untuk memanfaatkan layanan tersebut, begitupun dengan kunjungan ke Puskesmas dalam 
memanfaatkan PKPR, sedangkan yang di dapatkan selama ini hanya penyuluhan kesehatan terkait HIV AIDS dan juga Narkoba saja yang diberikan sekali setahun oleh petugas kesehatan.

Hal tersebut didukung oleh pernyataan pemegang program yang mengungkapkan bahwa pemanfaatan PKPR di sekolah masih seputar pemberian Komunikasi, Informasi, dan Edukasi (KIE) mengenai pencegahan masalah kesehatan, kepedulian remaja masih sangat kurang karena sulit dikumpulkan dalam pemberian KIE sehingga remaja belum mengetahui informasi terkait adanya layanan PKPR di Puskesmas, serta pemegang program menyadari bahwa kendala utama dari program PKPR yakni belum adanya pelatihan secara mendalam kepada petugas terkait mengenai cara menangani permasalahan kesehatan pada remaja sehingga pelaksanaan program di Puskesmas Jumpandang Baru belum maksimal.

Program PKPR merupakan wadah yang diberikan oleh pemerintah untuk mengatasi permasalahan kesehatan remaja, namun fakta dilapangan membuktikan bahwa rendahnya kunjungan remaja dalam mengakses program tersebut merupakan kondisi yang harus ditangani oleh berbagai pihak yang peduli terhadap remaja, karena kurangnya pemahaman dari petugas terkait mengenai informasi keberadaan PKPR, sehingga dampak yang ditimbulkan adalah minimnya pemanfaatan terkait pelayanan kesehatan oleh remaja sebagai sasaran utama keberlangsungan program tersebut dalam memanfaatkan PKPR, berdasarkan pengetahuan yang didapatkan melalui informan maka tujuan program PKPR harusnya lebih dipahami oleh remaja agar lebih peduli untuk di implementasikan dalam kehidupan sehari-sehari.

Hasil penelitian ini sejalan dengan penelitian Hilda Asmariva (2015) yang membahas tentang implementasi program pelayanan kesehatan peduli remaja (pkpr) di Puskesmas Senapelan kota Pekanbaru, hasil penelitian ini mengungkapkan bahwa siswi SMP 2 Snapelan belum terlalu paham mengenai pelaksanaan program PKPR. Pengetahuan mereka mengenai PKPR masih berupa pelayanan kesehatan kepada orang sakit sehingga pelaksanaan program PKPR belum terlaksana secara menyeluruh (Asmariva Febri, 2015)

Hasil penelitian ini juga sejalan dengan penelitian Kadek Alit (2013) yang membahas tentang peranan program pkpr (pelayanan kesehatan peduli remaja) terhadap kesehatan reproduksi remaja di Kecamatan Buleleng menyatakan bahwa kurangnya pengetahuan remaja mengenai keberadaan PKPR ini berdampak pada tidak maksimalnya pelayanan, konseling dan penyuluhan mengenai kesehatan remaja (Ni Luh Kadek Alit Arsani, Ni Nyoman Mestri Agustini, 2013)

2. Faktor pendukung (Fasilitas pelayanan Kesehatan)

Fasilitas kesehatan menurut Peraturan Presiden RI No. 12 tahun 2013 tentang jaminan Kesehatan adalah fasilitas pelayanan kesehatan yang digunakan untuk menyelenggarakan upaya pelayanan kesehatan perorangan, baik promotif, preventif, kuratif, maupun rehabilitatif yang dilakukan oleh pemerintah, pemerintah daerah, dan masyarakat, pemanfaatan kelengkapan fasilitas pelayanan kesehatan umumnya berkaitan dengan penampilan fisik fasilitas kesehatan, petugas kesehatan, maupun sarananya. Kebersihan dan kerapihan juga merupakan faktor penting untuk menarik pasien yang dapat menjamin keberlangsungan pelayanan (Kemenkes RI, 2011).

Pelayanan kesehatan peduli remaja adalah layanan yang ditujukan dan dapat dijangkau oleh remaja, menyenangkan, menerima remaja dengan tangan terbuka, menghargai remaja, menjaga kerahasiaan, peka akan kebutuhan terkait dengan kesehatannya, serta efektif dan efisien dalam 
memenuhi kebutuhan tersebut. Singkatnya, PKPR adalah pelayanan kesehatan kepada remaja yang mengakses semua golongan remaja, dapat diterima, sesuai, komprehensif, efektif dan efisien (IHME, 2013).

Layanan konseling menjadi fasilitas terpenting pada PKPR karena merupakan salah satu syarat kriteria menjadi Puskesmas mampu melaksanakan PKPR, yakni memberikan pelayanan konseling pada semua remaja yang memerlukan konseling dan kontak langsung dengan petugas, disamping itu terdapat pula layanan KIE yang berfungsi untuk memberikan informasi kesehatan di dalam maupun di luar Puskesmas sebanyak dua kali setahun yang di dalamnya meliputi media KIE seperti poster, leflet, buku saku dan juga brosur.(Department of Maternal Newborn Child and Adolescent Health, 2012).

Informasi yang didapatkan dari remaja yang memanfaatkan layanan PKPR di Puskemas menyatakan bahwa fasilitas pelayanan kesehatan di Puskesmas Jumpandang Baru sudah memadai karena mereka mendapatkan pelayanan konseling, pemeriksaan penunjang, buku saku, dan brosur dari petugas, serta fasilitas PKPR yang ada di Puskesmas sangat memadai, hanya saja perlu ditingkatkan terkait pemanfaatan PKPR agar lebih menarik karena pelayanannya gratis sehingga mengurangi beban remaja dalam memelihara dan memeriksakan kesehatannya.

Hal tersebut di dukung pula oleh pernyataan dari konselor bahwa fasilitas yang terdapat di puskesmas sangat lengkap meliputi ruangan konseling, terapi methadone (narkoba), pemeriksaan penunjang kesehatan serta media KIE sehingga secara keseluruhan dapat menunjang program PKPR di dalam gedung Puskesmas, tetapi belum sepenuhnya dilaksanakan di luar gedung Puskesmas terutama pada pelaksanaan program di sekolah binaan.
Fasilitas yang lengkap, namun tidak digunakan secara efektif akan mempengaruhi pelaksanaan program PKPR. Hal ini disebabkan karena keefektifan dalam pemanfaatan fasilitas sangat menunjang alur pelayanan yang mampu menarik perhatian remaja. Namun hal ini tidak didapatkan oleh remaja yang berada di sekolah ketika mendapatkan penyuluhan dari petugas, mereka mengeluhkan tentang ketidaklengkapan fasilitas yang diberikan, salah satunya yaitu mereka tidak mendapatkan brosur dan poster saat pemberian KIE di sekolah, dan informasi tentang KIE hanya diberikan satu tahun sekali itupun dalam kondisi ruangan yang tidak memadai (terlalu banyak peserta) sehingga suasananya tidak kondusif dan informasinya tidak terserap dengan maksimal hal ini mempengaruhi pelaksanaan PKPR yang belum efektif, seharusnya fasilitas yang tepat digunakan adalah media online seperti website yang berperanan sebagai akses informasi masa kini untuk menarik perhatian remaja agar memanfaatkan program PKPR .

Penelitian ini tidak sejalan dengan penelitian Rohmayanti (2015) yang membahas Pelayanan kesehatan peduli remaja menurut perspektif remaja di Kota Magelang menyatakan bahwa konseling dan penyuluhan yang menyenangkan akan menarik perhatian remaja untuk datang berkunjung, selain itu pemberian media KIE seperti leaflet yang bisa mereka bawa pulang ke rumah juga menjadi suatu hal yang menarik perhatian remaja (Rohmayanti, Rahman and Nisman, 2015).

Hasil penelitian ini di dukung oleh penelitian Uswatun Hasanah (2016) yang membahas mengenai gambaran standar pelayanan kesehatan peduli remaja pada Puskesmas di Kota Makassar yang menunjukkan bahwa sebagian besar Puskesmas sudah memiliki fasilitas pelayanan yang memadai namun belum di gunakan secara efektif terutama dalam 
pelaksanaan pelayanan kesehatan peduli remaja (Hasanah Uswatun P S, Stang).

Berdasarkan hasil penelitian diatas mengenai fasilitas pelayanan kesehatan dalam pemanfaatan program PKPR di puskesmas sudah memadai namun perlu diefektifkan terutama di sekolah agar pelaksanaan program PKPR dapat berjalan maksimal.

3. Faktor Pendorong (Dukungan Petugas)

Dukungan petugas kesehatan peduli remaja adalah dukungan yang mampu menunjukan sikap menghargai dan tidak membedakan, mempunyai kompetensi sesuai dengan bidangnya, dan mempunyai motivasi untuk menolong dan memberikan dukungan pada remaja, dapat dipercaya dan dapat menjaga kerahasiaan, serta mampu memberikan informasi dan dukungan yang cukup hingga remaja dapat memutuskan pilihan yang tepat untuk mengatasi masalahnya atau memenuhi kebutuhannya (Dirjen Bina Kesehatan Anak, 2015).

Dukungan petugas dalam penelitian ini menurut remaja baik karena petugas mampu memberikan perubahan yang dapat berpengaruh terhadap perilaku remaja dalam pemanfaatan program PKPR kearah yang lebih baik, sikap petugas yang ramah, tidak mendiskriminasi, dan peduli terhadap kesehatan remaja sehingga dapat menimbulkan kenyamanan pada diri remaja ketika berkunjung di Puskesmas.

Hal ini dibenarkan oleh pernyataan pendamping sebaya yang menyatakan bahwa petugas di Puskesmas sangat ramah terhadap remaja, tidak membedabedakan satu dengan yang lain, dan selalu memberikan dorongan ke remaja untuk selalu berkonsultasi dengan petugas terkait masalah kesehatannya, adapun kebijakan yang peduli remaja dengan mengadakan kerjasama lintas sektoral yang meliputi LSM dan forum pemerhati remaja, juga Puskesmas jejaring lainnya, Namun masih belum adanya pelatihan khusus dari pemerintah terkait program
PKPR sehinga menjadi kendala dalam pelaksanaannya.

Dukungan semacam ini hendaknya petugas pertahankan, ditingkatkan, dan di berlakukan secara keseluruhan sehingga seluruh lapisan remaja dapat merasakan tingkat kenyamanan yang sama dalam pemanfaatan layanan PKPR baik itu remaja yang berkunjung ke Puskesmas maupun yang mendapatkan penyuluhan di sekolah. Sebab hal ini didapatkan dari remaja di sekolah yang mengeluhkan tentang petugas kesehatan yang berkunjung ke sekolah saat melakukan penyuluhan, remaja di sekolah menganggap bahwa dukungan petugas masih kurang karena tidak berbaur kepada remaja dan tidak peduli dengan pertanyaan yang dilontarkan pada saat pemberian Komunikasi Informasi dan Edukasi, dan juga penyampaian materi mengenai kesehatan belum jelas karena petugas kesehatan menggunakan bahasa yang sulit dimengerti oleh remaja, hal ini mempengaruhi keinginan remaja untuk mengakses layanan PKPR. Informasi lainnya yang berkaitan dengan kurangnya dukungan petugas kesehatan diungkapkan oleh informan bahwa pentingnya pemanfaatan program PKPR bagi kesehatan remaja tidak disampaikan langsung oleh petugas, hanya pemberian KIE mengenai HIV AIDS dan Narkoba disekolah serta sikap petugas yang tidak ramah dan jarang senyum dalam melayani remaja pada pelaksanaan PKPR disekolah yang seharusnya dapat mengayomi dan mengarahkan remaja, agar mau dan mampu memanfaatkan layanan PKPR Pelaksanaan program PKPR belum berjalan dengan optimal karena dukungan petugas hanya pada konseling di Puskesmas, tetapi tidak terlaksana seperti memberikan pelayanan konseling pada semua remaja yang memerlukan konseling yang kontak dengan petugas, melakukan pembinaan pada minimal satu sekolah dalam setahun di sekolah umum atau sekolah berbasis agama, dengan minimal melaksanakan 
kegiatan KIE dua kali setahun, Melatih kader kesehatan remaja di sekolah sebanyak $10 \%$ dari jumlah murid di sekolah binaan. Hal ini didukung dengan hasil penelitian Rini Winangsih (2016) yang membahas mengenai persepsi remaja terhadap pelayanan kesehatan peduli remaja menyatakan minimnya pemanfaatan PKPR dipengaruhi jam sekolah yang tidak sesuai dengan jam buka puskesmas. Kebijakan dari sekolah yang tidak memprioritaskan kesehatan remaja serta sikap yang ditunjukkan oleh petugas kesehatan kurang ramah dan berwajah muram terkait dalam pelayanan KIE maupun kegiatan klinik PKPR di dalam gedung Puskesmas, hal tersebut menjadi faktor pendorong pada remaja untuk tidak memanfaatkan pelayanan klinik PKPR di puskesmas.

Penyebab program PKPR tidak berjalan dengan efektif di Puskesmas Jumpandang Baru dipengaruhi oleh faktor internal dan juga faktor eksternal pada perilaku remaja dalam pemanfaatan program PKPR yang meliputi faktor internal adalah pengetahuan informan yang belum menyeluruh terkait program PKPR, sosialisasinya masih kurang kepada remaja di sekolah, sehingga hal tersebut mempengaruhi kunjungan remaja ke Puskesmas rendah, sedangkan untuk faktor eksternal adalah dukungan petugas kesehatan yang belum terarah secara fokus serta petugas harus mengetahui orientasi mengenai waktu dalam pendekatan terhadap perilaku remaja untuk melancarkan program PKPR.

\section{KESIMPULAN}

Faktor predisposisi pada perilaku remaja dalam pemanfaatan program pelayanan kesehatan peduli remaja terkait pengetahuan yaitu belum menyeluruh karena remaja disekolah belum mengetahui adanya layanan PKPR di Puskesmas Jumpandang Baru sehingga belum memanfaatkan layanan tersebut.
Faktor pendukung pada perilaku remaja dalam program pelayanan kesehatan peduli remaja terkait fasilitas pelayanan kesehatan yaitu sudah memadai namun perlu diefektifkan terutama di sekolah agar pelaksanaan program PKPR dapat berjalan maksimal.

Faktor pendorong pada perilaku remaja dalam pemanfaatan program PKPR terkait dukungan petugas kesehatan adalah belum sepenuhnya merangkul remaja secara keseluruhan karena perlakuan yang didapatkan remaja dari pertugas kesehatan ketika memberikan penyuluhan di sekolah berbeda dengan remaja yang berkunjung di Puskesmas sehingga hal tersebut dapat mempengaruhi perilaku mereka dalam pemanfaatan program PKPR.

\section{UCAPAN TERIMA KASIH}

Penulis mengucapkan terima kasih banyak kepada Kementerian Riset Teknologi dan Perguruan Tinggi/BRIN atas pemberian dana penelitian pada skim Penelitan Dosen Pemula (PDP) tahun anggaran 2020, dan juga terima kasih sebagai seluruh pihak terkait kepada Dinas Pemerintahan Kota Makassar, Kepala Puskesmas Jumpandang Baru dan staff jajarannya serta seluruh Partisipan dan Informan.

\section{DAFTAR PUSTAKA}

Asmariva Febri, H. Y. (2015) 'Implementasi Program Pelayanan Kesehatanpeduli Remaja (Pkpr) Di Puseksmas Senapelan Kecamatan Senapelan Kota Pekanbaru', Jurnal Online Mahasiswa (JOM) Bidang Ilmu Sosial Dan Ilmu Politik.

Atuyambe, L. M. Et Al. (2015) 'Understanding Sexual And Reproductive Health Needs Of Adolescents: Evidence From A Formative Evaluation In Wakiso District, Uganda Adolescent Health', 
Reproductive Health. Doi: 10.1186/S12978-015-0026-7.

Baso, B. (2019) Kasus HIV/AIDS, Www.Mediasulsel.Com.

BKKBN Dan BPS (2017) 'Survei Demokrasi

Dan Kesehatan Indonesia', In Kesehatan Reproduksi Remaja. Jakarta.

Department Of Maternal Newborn Child And Adolescent Health (2012) 'Making Health Services Adolescent Friendly - Developing National Quality Standards For Adolescent Friendly Health Services', World Health Organization.

Dirjen Bina Kesehatan Anak (2015) Pedoman Pelayanan Kesehatan Peduli Remaja Di Puskesmas. Kemenkes R. Jakarta.

Hasanah Uswatun P S, Stang, M. (No Date) 'Pelaksanaan Standar Nasional Pelayanan Kesehatan Peduli Remaja Pada Puskesmas Di Kota Makassar Universitas Hasanuddin Ilmu Biostatistik Volume 10 No 2', Universitas Hasanuddin Ilmu Biostatistik, Volume 10(No 2).

IHME (2013) 'Peraturan Presiden No.12 Tahun 2013 Tentang Jaminan Kesehatan',

Kemenkes RI (2011) Modul Pelatihan Pelayanan Kesehatan Peduli Remaja (PKPR) Bagi Petugas Konseling. Edited By D. B. G. Dan K. I. Dan Anak. Jakarta.

Ni Luh Kadek Alit Arsani, Ni Nyoman Mestri Agustini, I. K. I. P. (2013) 'Peranan Program Pkpr ( Pelayanan Kesehatan Peduli Remaja ) Terhadap Kesehatan Reproduksi Remaja Di', Jurnal Ilmu Sosial Dan Humaniora.

Rohmayanti, R., Rahman, I. T. And Nisman,
W. A. (2015) 'Pelayanan Kesehatan Peduli Remaja Menurut Perspektif Remaja Di Kota Magelang', Jurnal Kesehatan Reproduksi. Doi: 10.22146/Jkr.6900.

Sugioyo (2010) Metode Penelitian Kuantitatif Kualitatis Dan $R \& D$. Cetakan Ke. Bandung: CV Alfabet. 